\title{
Análise da eficiência energética da envoltória de um projeto padrão de uma agência bancária em diferentes zonas bioclimáticas brasileiras
}

Analysis of the energy efficiency of the building envelope of a bank branch standard design in different Brazilian bioclimatic zones

\section{Eduardo Leite Krüger Fabiano Mori}

\section{Resumo}

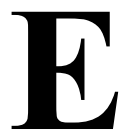

ste trabalho analisou e classificou o desempenho energético da envoltória de um projeto padrão de uma agência bancária por meio de parâmetros do Método Prescritivo do Regulamento Técnico da Qualidade do Nível de Eficiência Energética de Edifícios Comerciais, de Serviços e Públicos, em diferentes zonas bioclimáticas brasileiras. Nas situações em que o edifício apresentou oportunidades de melhoria, foram testadas estratégias bioclimáticas em relação às aberturas envidraçadas, tais como sombreamentos vertical e horizontal (AVS e AHS) e fator solar dos vidros (FS). Em apenas seis situações verificou-se que a envoltória do projeto padrão original não atingiu o nível "A". Para esses casos, foram alterados fatores relacionados a AVS, AHS e FS nas equações do Método Prescritivo para obtenção de um valor do indicador de consumo da envoltória que a classificasse com o nível "A". Para avaliar o potencial de economia de energia elétrica do sistema de ar condicionado com as alterações propostas, foi realizada a simulação computacional, considerando o projeto original e o projeto otimizado. Os resultados da simulação mostraram que é possível uma economia de até $26,0 \%$ no consumo de energia elétrica para o projeto otimizado com a fachada principal orientada para o Oeste na cidade de Curitiba/PR. Para a implantação da agência com a fachada principal para o Oeste na cidade de Brasília/DF, a simulação apontou uma economia de até $30,5 \%$ com a alteração do FS dos vidros.

Palavras-chave: Eficiência energética em edificações. Arquitetura bioclimática. Simulação termoenergética.

Eduardo Leite Krüger Programa de Pós-Graduação em Engenharia Civil, Departamento de Construção Civil Universidade Tecnológica Federal do

Av. Sete de Setembro, 3165, Rebouças Curitiba - PR - Brasil CEP 80230-901 Tel.: (41) 3310-4725 Ramal: 4725 E-mail: ekruger@utfpr.edu.br

Fabiano Mori Caixa Econômica Federal Rua J osé Loureiro, 195, Centro Curitiba - PR - Brasil CEP 80010-000

E-mail: fabiano.mori@gmail.com

Recebido em 17/02/12

Aceito em 03/09/12

\section{Abstract}

This study analyses the energy performance of the building envelope of a bank branch standard project, according to the requirements of the Prescriptive Method of the Brazilian Technical Regulation for Energy Efficiency Labeling of Commercial, Service and Public Buildings, for different bioclimatic zones in Brazil. Whenever the building presented opportunities for improvement, bioclimatic strategies were tested regarding glazed openings, such as shading devices (vertical and horizontal), and the glazing solar factor. Only in six cases the envelope did not meet the "A" efficiency level requirements. Under such conditions, parameters related to shading devices and to the glazing solar factor were changed in the equations of the prescriptive method for reaching the " $A$ " level. For the purpose of evaluating the potential of electric energy savings due to air-conditioning for each change tested, simulations were for the original and for the optimized project. Simulation results indicated possible savings in electricity consumption of up to $26.0 \%$ for the optimized project with main façade facing West in Curitiba. For a West-facing main façade in Brasilia, potential savings were $30.5 \%$ by changing the solar factor of glazing.

Keywords: Energy efficiency in buildings. Bioclimatic architecture. Thermal Simulation. 


\section{Introdução}

Lamberts, Dutra e Pereira (1997) conceituam eficiência energética como “a obtenção de um serviço com baixo dispêndio de energia. Portanto, um edifício é mais eficiente energeticamente que outro quando proporciona as mesmas condições ambientais (internas) com menor consumo de energia". As edificações apresentam oportunidades expressivas de redução de custos e economia de energia por meio do uso de produtos tecnologicamente mais eficientes e modernos, ações de conscientização de seus usuários ou ainda pela implantação de sistemas de gerenciamento da energia utilizada. A observância dos novos conceitos da arquitetura bioclimática e de eficiência energética, desde a fase de projeto das novas edificações e/ou nos de adequação de ambientes já existentes contribuem para melhorar o desempenho técnico e econômico destas edificações.

Dados do BEN - Balanço Energético Nacional 2011, ano base 2010 - (EMPRESA..., 2011) mostram que os segmentos residenciais, comerciais e de serviços públicos representam $46,9 \%$ do consumo de energia elétrica no Brasil.

Estima-se que todo o custo operacional de um edifício ao longo de sua vida supere o custo total de construção do mesmo, sendo que energia elétrica é um dos principais custos operacionais. Por isso é importante investir em produtos tecnologicamente mais eficientes, ou mudanças arquitetônicas que visem conservar energia, que se pagarão ao longo dos anos com a economia gerada por eles, aliados a investimentos em conscientização dos usuários (LAMBERTS et al., 1997).

O desconhecimento de soluções arquitetônicas adequadas para a otimização das condições de conforto (ou diminuição do desconforto) em edificações acaba resultando em ambientes termicamente desfavoráveis. As conseqüências são, em geral, drásticas: prédios que apresentam um grande consumo de energia para condicionamento de ar no verão ou para calefação no inverno, ou situações em que a simples permanência no ambiente, seja ele local de trabalho ou de moradia, torna-se uma experiência bastante desagradável do ponto de vista do conforto de seus ocupantes. Indo-se um pouco mais além na análise das conseqüências, poder-seá verificar a diminuição do rendimento nas atividades a serem realizadas, no caso de ambientes de trabalho, ou mal-estar físico, no caso de moradias.
Há a necessidade permanente de se conservar energia, não apenas para evitar desperdícios, mas para que não sejam necessários novos investimentos em obras de geração. Além disso, o setor da construção civil apresenta diversas distorções no que se refere a desperdícios de energia na fase de construção e durante a gestão de prédios. Expectativas de redução de consumo através de medidas de eficiência energética em edificações apontam para um potencial relativamente baixo dentro de um período de 20 anos (no setor residencial e de serviços, projeções para 2030), cerca de 10\%, comparativamente à iluminação pública, por exemplo, com 51\% (MME/EPE, 2007). Sabe-se, no entanto, que a construção civil apresenta inúmeras carências quanto à necessidade de racionalizar o processo construtivo, com iniciativas como lean construction (OLIVEIRA et al., 2010), estratégias para redução de resíduos (AGOPYAN et al., 1998) ou de diminuição da energia embutida em materiais de construção (KRONKA, 1998), dentre outras. Tais distorções afetam também a fase de uso das edificações, levando a elevado consumo em equipamentos de iluminação, muitas vezes de baixa eficiência luminosa, e ao emprego generalizado de climatização artificial em prédios comerciais, públicos e de serviços. Potenciais de redução de consumo em iluminação artificial, no caso brasileiro, são grandes, chegando a $14,5 \%$ no setor industrial e a $15,3 \%$ e $47,7 \%$, nos setores comercial e público e no setor residencial, respectivamente (MINISTÉRIO...; EMPRESA..., 2007). Para os últimos dois setores, os potenciais de conservação em climatização artificial são de $8 \%$ e de 14,3\%, respectivamente (op. cit.). Complementarmente, uma maior compreensão dos processos térmicos que ocorrem no interior de edificações pode atuar diretamente na redução do consumo de energia para condicionamento artificial de ambientes durante a gestão dos edifícios, podendo representar uma redução de insumos energéticos no setor da construção civil.

A certificação de edificações é novidade no Brasil, mas já é um tema bastante difundido e aplicado em outros países. No caso do RTQ-C, há a previsão que o mesmo tenha caráter compulsório para todas as novas edificações a serem construídas, dentro de um prazo a ser definido pelos órgãos competentes.

Classificar o desempenho energético de edifícios está se tornando um aspecto de extrema importância do edifício em operação. Um edifício com uma alta classificação pode ser elegível para um reconhecimento especial através de um programa obrigatório ou voluntário. Este 
reconhecimento valoriza o imóvel, aumentando seu valor de venda ou de aluguel. Além disso, os sistemas de classificação também ajudam a identificar edifícios que consomem muita energia, fornecendo, então, oportunidade para que medidas de conservação energética possam ser tomadas. $\mathrm{O}$ sistema de classificação de edifícios é um fenômeno crescente e usado por vários países (OLOFSSON; MEIER; LAMBERTS, 2004).

Praticamente todos os países da Europa, além dos Estados Unidos, Canadá, Austrália, Japão e China possuem um sistema de avaliação e classificação de desempenho ambiental de edifícios (SILVA, 2003). Nesses casos, as normas de eficiência energética de edificações não-residenciais apresentam duas abordagens: uma prescritiva e outra por desempenho. Costumam apresentar ainda uma abordagem alternativa, que pode envolver um sistema de trocas ou avaliações específicas por profissionais devidamente qualificados (CARLO, 2008).

A abordagem prescritiva estabelece limites ou indica soluções que atendem ao exigido para aprovação da edificação proposta, envolvendo propriedades físicas dos componentes da envoltória, como transmitância térmica, fator solar de vidros e resistência térmica de isolamentos.

O RTQ-C - Regulamento Técnico da Qualidade para Eficiência Energética de Edifícios Comerciais, de Serviços e Públicos (INSTITUTO..., 2010) conceitua edifícios comerciais e de serviços como "aqueles, públicos e/ou privados, usados com finalidade que não a residencial ou industrial".

O processo de certificação do RTQ-C possui caráter voluntário e especifica métodos para classificação de edifícios comerciais, de serviços e públicos quanto a sua eficiência. Aplica-se para edifícios com área mínima de $500 \mathrm{~m}^{2}$ ou com tensão de abastecimento superior a 2,3 kV, contendo ou não sistema de climatização artificial. Seu objetivo é criar condições para a etiquetagem voluntária do nível de eficiência energética dessas edificações.

No estudo de Carlo (2008), as equações que fornecem o Indicador de Consumo da Envoltória (ICenv) foram utilizadas na "Regulamentação para Etiquetagem Voluntária de Nível de Eficiência Energética em Edificações Comerciais, de Serviços e Públicos", da qual originou-se o RTQ$\mathrm{C}$, tendo sido desenvolvidas para climas brasileiros diversos de acordo com o Zoneamento Bioclimático Brasileiro. $\mathrm{O}$ item da envoltória indica o seu nível de eficiência energética segundo os parâmetros de classificação do Inmetro, sendo o nível mais elevado eficiência "A" e o mais baixo, eficiência " $E$ ". O nível de eficiência é classificado de "A" a "E" para três quesitos. Calcula-se também uma pontuação geral para a edificação. Para determinação do nível de eficiência global da edificação são analisados os seguintes itens com seus respectivos pesos:
(a) envoltória $(30 \%)$;
(b) sistema de iluminação (30\%), e
(c) sistema de condicionamento de ar (40\%).

O quesito "envoltória" refere-se à envoltória do edifício proposto. Deve ser calculado por fórmula que usa as seguintes variáveis:
(a) área de janelas;
(b) existência e dimensões de proteções solares;
(c) tipos de vidro;
(d) dimensões da edificação; e
(e) zoneamento bioclimático brasileiro.

Edifícios que possuem áreas não condicionadas devem comprovar por simulação computacional que nesses locais a temperatura está dentro da zona de conforto durante um considerável percentual de tempo das horas de uso durante o ano.

Os conceitos e definições das variáveis das equações do ICenv são os constantes no RTQ-C e disponíveis no Inmetro (INSTITUTO..., 2010)

O objetivo deste artigo é avaliar a eficiência energética da envoltória de um projeto padrão de uma agência bancária em diferentes zonas bioclimáticas brasileiras, por meio de parâmetros do RTQ-C do Inmetro.

\section{Metodologia}

Com base no projeto padrão de uma agência bancária, foi realizado o levantamento dos dados necessários para a aplicação das equações dos indicadores de consumo da envoltória (ICenv) do Método Prescritivo do RTQ-C para as oito zonas bioclimáticas brasileiras, considerando-se ainda as quatro possibilidades de implantação da agência, de acordo com a orientação solar da fachada principal (a qual possui a maior área envidraçada). Adicionalmente, foram avaliadas as características dos materiais especificados para a construção da agência bancária, dados necessários para a obtenção dos valores de transmitância térmica e absortância das paredes externas e da cobertura. Nas situações em que o edifício apresentou oportunidades de melhoria (quando a envoltória não atingiu a classificação com o nível "A"), foram testadas estratégias bioclimáticas em relação às aberturas envidraçadas, tais como sombreamentos (AVS e AHS) e alteração do fator 
solar (FS) dos vidros. Para avaliação do potencial de economia de energia elétrica do sistema de ar condicionado com as alterações propostas, foi

\section{Descrição do objeto de estudo}

O projeto padrão analisado é de uma agência bancária de instituição financeira com atuação em todo o território brasileiro. A implantação do projeto foi prevista para qualquer localidade brasileira, necessitando-se de um terreno com dimensões de $40 \mathrm{~m} \times 20 \mathrm{~m}$. A área construída total é de $565,72 \mathrm{~m}^{2}$, em pavimento único, com sistema construtivo do tipo "steel frame". A Figura 1 mostra a maquete eletrônica da agência padrão.

A fachada principal (elevação frontal) possui a maior área envidraçada quando comparada às realizada a simulação computacional com o programa EnergyPlus considerando-se o projeto padrão original e o projeto otimizado. demais elevações (lateral esquerda e posterior). Já a elevação lateral direita fica junto à divisa (limite do terreno), não possuindo aberturas externas. A Figura 2 mostra o desenho das elevações do projeto padrão.

\section{Implantação do projeto de acordo com a orientação solar da fachada principal}

Para o estudo foram adotadas quatro possibilidades de implantação de projeto de acordo com a orientação solar da fachada principal, conforme mostrado na Figura 3.

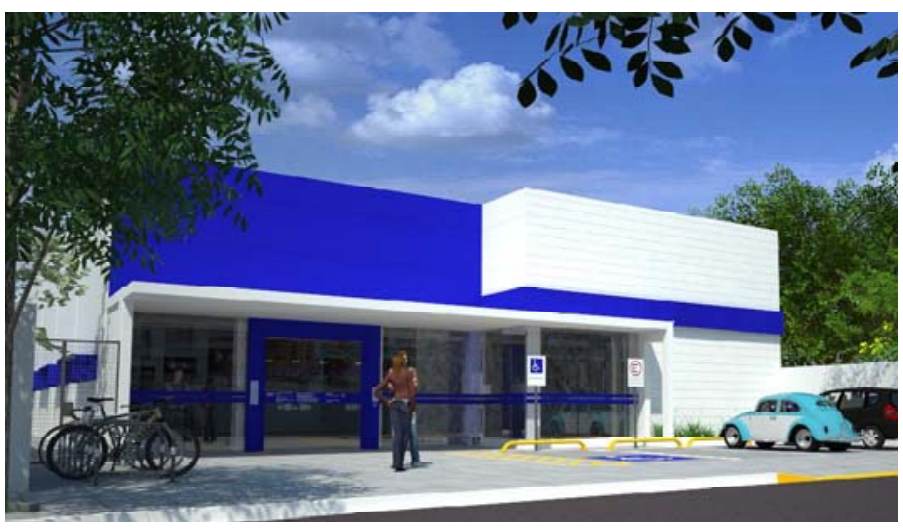

Figura 1 - Maquete eletrônica da fachada principal da agência bancária

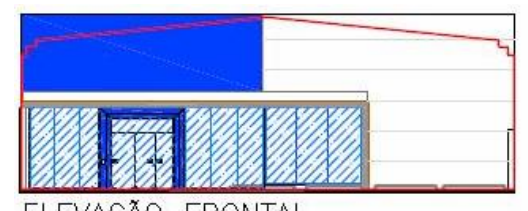

ELEVACAO FRONTAL

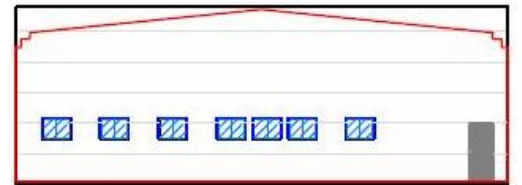

ELEVAÇAO POSTERIOR
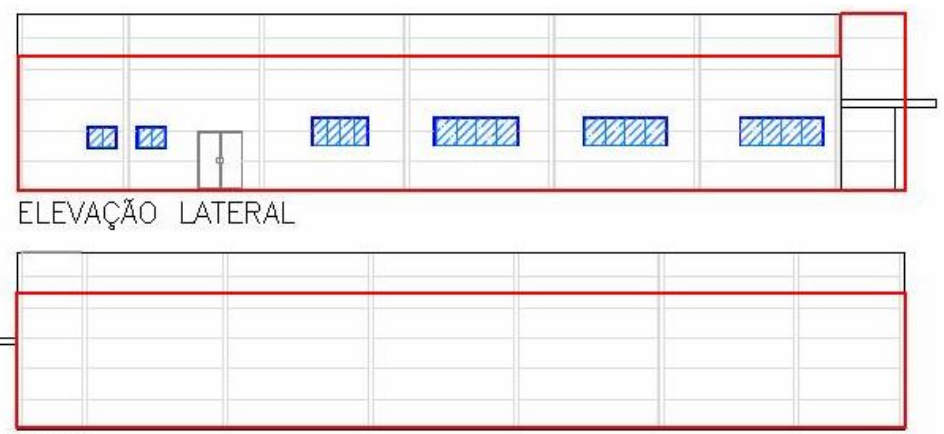

DIVISA

Figura 2 - Elevações do projeto padrão da agência bancária 


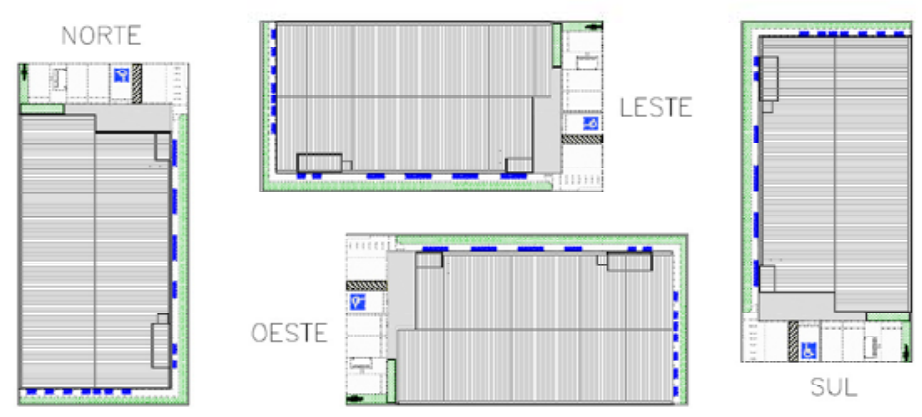

Figura 3 - Implantação do projeto padrão de acordo com a orientação solar da fachada principal

Tabela 1 - Áreas da edificação

\begin{tabular}{c|c|c|c|c|c}
\hline $\begin{array}{c}\text { Área } \\
\text { total } \\
\left(\mathbf{m}^{\mathbf{2}}\right)\end{array}$ & $\begin{array}{c}\text { Área } \\
\text { útil } \\
\left(\mathbf{m}^{\mathbf{2}}\right)\end{array}$ & $\begin{array}{c}\text { Área } \\
\text { condicionada } \\
\left(\mathbf{m}^{\mathbf{2}}\right)\end{array}$ & $\begin{array}{c}\text { Área de } \\
\text { permanência } \\
\text { transitória não } \\
\text { condicionada }\left(\mathbf{m}^{\mathbf{2}}\right)\end{array}$ & $\begin{array}{c}\text { Área de ambientes } \\
\text { de permanência } \\
\text { prolongada não } \\
\text { condicionados }\left(\mathbf{m}^{\mathbf{2}}\right)\end{array}$ & $\begin{array}{c}\text { Área de } \\
\text { projeção do } \\
\text { edifício }\left(\mathbf{m}^{\mathbf{2}}\right)\end{array}$ \\
\hline 565,72 & 532,20 & 413,33 & 118,87 & 0,00 & 565,72 \\
\hline
\end{tabular}

As equações para classificação do nível de eficiência energética da envoltória utilizada no Método Prescritivo do RTQ-C utilizam variáveis que dependem da forma da edificação (área total construída, volumetria, altura) e também outras variáveis que podem ser alteradas pelo projetista (área de vidros, fator solar, sombreamentos horizontais e verticais) que são influenciadas diretamente pelas características bioclimáticas da região. Para a análise do projeto padrão, foram levantados os seguintes dados do projeto arquitetônico:

(a) área de fachadas e da cobertura (envoltória da edificação);

(b) área de projeção da cobertura; área de projeção da edificação;

(c) volume total da edificação;

(d) área de piso;

(e) área de aberturas envidraçadas;

(f) percentual de abertura das fachadas;

(g) orientação solar das fachadas;

(h) fator solar das aberturas envidraçadas;

(i) ângulos de sombreamento (proteções solares verticais e horizontais);

(j) localização (zoneamento bioclimático brasileiro).

A Tabela 1 apresenta os valores das áreas da edificação (total, útil, condicionada, de permanência transitória não condicionada, de ambientes não condicionados de permanência prolongada e de projeção do edifício).

Por se tratar de ambiente confinado devido à natureza da edificação (agência bancária), todos os ambientes de permanência prolongada são condicionados artificialmente. Somente os ambientes de permanência transitória não possuem condicionamento de ar artificial (corredores, sanitários, copa, depósito, almoxarifado, arquivo).

A Tabela 2 apresenta o volume total da edificação, que é obtido somando-se o volume do térreo (área total do pavimento multiplicada pela altura do pédireito) e o volume da cobertura (área da seção transversal da cobertura multiplicada pelo comprimento do telhado).

A Tabela 3 mostra a área das paredes externas de cada elevação, assim como a área de aberturas envidraçadas em cada uma das elevações.

A Tabela 4 apresenta a área total da envoltória e suas duas componentes (a área das paredes externas e a área da cobertura), para utilização no cálculo do fator de forma (FF).

A Tabela 5 mostra o fator de forma (FF) do projeto padrão. O FF é adimensional (para aplicação nas equações do ICenv), sendo obtido pela relação entre a área total da envoltória e o volume total da edificação.

A Tabela 6 mostra o fator altura (FA) do projeto padrão. O FA também é adimensional, sendo obtido pela relação entre a área de projeção da edificação e a área total de piso. 
Tabela 2 - Volume total da edificação

\begin{tabular}{c|c|c}
\hline Térreo $\left(\mathbf{m}^{\mathbf{3}}\right)$ & Cobertura $\left(\mathbf{m}^{\mathbf{3}}\right)$ & Volume total Vtot $\left(\mathbf{m}^{\mathbf{3}}\right)$ \\
\hline $2.772,03$ & 537,75 & $3.309,78$ \\
\hline
\end{tabular}

Tabela 3 - Área das paredes externas

\begin{tabular}{c|c|c|c}
\hline Elevação & $\begin{array}{c}\text { Área total } \\
\left(\mathbf{m}^{\mathbf{2}}\right)\end{array}$ & $\begin{array}{c}\text { Área de } \\
\text { vidros }\left(\mathbf{m}^{\mathbf{2}}\right)\end{array}$ & $\begin{array}{c}\text { PAF (\%) percentual de área de } \\
\text { abertura da fachada }\end{array}$ \\
\hline Frontal & 107,43 & 31,04 & 28,89 \\
Lateral & 162,93 & 17,47 & 10,72 \\
Posterior & 107,43 & 4,31 & 4,02 \\
Divisa & 159,40 & 0,00 & 0,00 \\
Total & 537,19 & 52,83 & 9,83 \\
\hline
\end{tabular}

Tabela 4 - Área da envoltória

\begin{tabular}{c|c|c}
\hline Área das paredes externas $\left(\mathbf{m}^{\mathbf{3}}\right)$ & Área da cobertura $\left(\mathbf{m}^{\mathbf{3}}\right)$ & Área total da envoltória $\mathbf{( m}^{\mathbf{2}} \mathbf{)}$ \\
\hline 537,19 & 569,27 & $1,106,46$ \\
\hline
\end{tabular}

Tabela 5 - Fator de Forma

\begin{tabular}{c|c|c}
\hline $\begin{array}{c}\text { Aenv - área total da } \\
\text { envoltória }\left(\mathbf{m}^{\mathbf{3}}\right)\end{array}$ & $\begin{array}{c}\text { Vtot - volume total } \\
\text { da edificação }\left(\mathbf{m}^{\mathbf{3}}\right)\end{array}$ & $\begin{array}{c}\text { FF - fator de forma } \\
\text { (Aenv/Vtot) }\end{array}$ \\
\hline $1.106,46$ & $3.376,51$ & 0,3277 \\
\hline
\end{tabular}

Tabela 6 - Fator Altura

\begin{tabular}{c|c|c}
\hline Ape - área de projeção da edificação $\left(\mathbf{m}^{\mathbf{3}}\right)$ & Atot - área total $\left(\mathbf{m}^{\mathbf{3}}\right)$ & FA - fator altura (Ape/Atot) \\
\hline 565,72 & 565,72 & 1,00 \\
\hline
\end{tabular}

Para cada zona bioclimática, de acordo com o RTQ-C, há duas equações para o cálculo do indicador de consumo da envoltória (ICenv) da edificação, que devem ser utilizadas em função da área de projeção da edificação (até $500 \mathrm{~m}^{2}$ ou superior). Também para cada equação devem ser respeitados os valores do fator de forma (FF) máximo para área de projeção menor que $500 \mathrm{~m}^{2} \mathrm{e}$ mínimo para áreas de projeção maiores que 500 $\mathrm{m}^{2}$. No caso do projeto padrão analisado, foram utilizadas as equações para edificações com área de projeção maior que $500 \mathrm{~m}^{2}$. O fator de forma adotado nas equações foi de 0,3673 , pois está acima dos fatores de forma mínimos definidos no RTQ-C. O fator altura adotado é 1,00, uma vez que a edificação é térrea.

A Tabela 7 mostra os valores dos componentes das variáveis arquitetônicas que influenciam nas aberturas envidraçadas para o projeto padrão. $\mathrm{O}$ fator solar dos vidros é a média ponderada dos valores de fator solar de cada tipo de vidro em função da área ocupada por essas aberturas envidraçadas. À exceção dos vidros da elevação frontal (laminados) e das janelas do salão de atendimento, os demais possuem FS igual a 0,87 (vidro transparente). Já os ângulos de sombreamento verticais (AVS) e horizontais (AHS) foram calculados em função dos elementos arquitetônicos que proporcionam sombreamento das aberturas envidraçadas, tais como brises, marquises e recuos.

De acordo com o RTQ-C, na equação para o cálculo do ICenv, o percentual de área de abertura na fachada total $\left(\mathrm{PAF}_{\mathrm{T}}\right)$ corresponde a um valor médio representativo do percentual de aberturas de todas as fachadas. Para o uso deste valor, primeiramente deve-se realizar o cálculo do PAF para a fachada oeste $\left(\mathrm{PAF}_{\mathrm{O}}\right)$ e em seguida o $\mathrm{PAF}_{\mathrm{T}}$. Se o $\mathrm{PAF}_{\mathrm{O}}$ for pelo menos $20 \%$ maior que o $\mathrm{PAF}_{\mathrm{T}}$, deve-se adotar o $\mathrm{PAF}_{\mathrm{O}}$ na equação. Para o projeto padrão em análise, o $\mathrm{PAF}_{\mathrm{O}}$ é maior que o $\mathrm{PAF}_{\mathrm{T}} \mathrm{em}$ $20 \%$ apenas para a implantação onde a fachada principal é voltada para a face oeste, conforme demonstrado na Tabela 8. Portanto, nas equações para a análise da envoltória, o $\mathrm{PAF}_{\mathrm{T}}$ utilizado deve ser de acordo com a coluna $\mathrm{PAF}_{\mathrm{T}}$ eq. da Tabela 8 .

\section{Materiais e sistema construtivo}

O sistema construtivo adotado no projeto padrão é baseado na tecnologia "steel frame". O objetivo da utilização dessa tecnologia é o ganho de tempo 
para a implantação de novas unidades, aliado à padronização dos materiais utilizados, reduzindo futuramente os custos com manutenção dos imóveis. Nesse projeto padrão também são utilizados materiais industrializados para os fechamentos das paredes externas, tais como placas e telhas isotérmicas. A Figura 4 mostra o sistema de montagem da estrutura "steel frame". A Figura 5 mostra $o$ detalhe das camadas componentes das paredes externas.

A cobertura da agência é composta com telhas metálicas do tipo "sanduíche", sendo a face externa uma chapa de aço tipo "galvalume" prépintada de branco, tendo logo abaixo uma camada com isolante térmico de poliuretano e a face inferior outra chapa de aço do tipo "galvalume". O entreforro pode ser considerado com uma câmara de ar não ventilada (onde se situam as instalações elétricas não aparentes, assim como as tubulações de ar condicionado). Logo abaixo, há a instalação de forro do tipo fibra mineral com propriedades termoacústicas. $\mathrm{Na}$ paginação desse forro são embutidas as luminárias e também as saídas de ar do sistema de climatização artificial da agência. A Figura 6 mostra o tipo de telha especificada para a cobertura. A Figura 7 mostra o tipo de forro mineral previsto no projeto padrão.

A Tabela 9 apresenta as características dos materiais construtivos das paredes externas e a Tabela 10 da cobertura.

Tabela 7 - Parâmetros das aberturas envidraçadas

\begin{tabular}{c|c|c}
\hline $\begin{array}{c}\text { FS - fator solar } \\
\text { médio dos vidros }\end{array}$ & $\begin{array}{c}\text { AVS - ângulo vertical } \\
\text { de sombreamento }\end{array}$ & $\begin{array}{c}\text { AHS - ângulo horizontal } \\
\text { de sombreamento }\end{array}$ \\
\hline 0,60 & $33,47^{\circ}$ & $18,47^{\circ}$ \\
\hline
\end{tabular}

Tabela 8 - PAF de acordo com a orientação solar da fachada principal

\begin{tabular}{c|c|c|c|c}
\hline Orientação solar & $\mathbf{P A F}_{\mathbf{T}}$ & $\mathbf{P A F}_{\mathbf{O}}$ & $\mathbf{P A F}_{\mathbf{T}}+\mathbf{2 0} \%$ & $\mathbf{P A F}_{\mathbf{T}} \mathbf{e q .}$ \\
\hline Norte & $9,8 \%$ & $0,0 \%$ & $11,8 \%$ & $9,8 \%$ \\
Leste & $9,8 \%$ & $4,0 \%$ & $11,8 \%$ & $9,8 \%$ \\
Sul & $9,8 \%$ & $10,7 \%$ & $11,8 \%$ & $9,8 \%$ \\
Oeste & $9,8 \%$ & $28,9 \%$ & $11,8 \%$ & $28,9 \%$ \\
\hline
\end{tabular}

Figura 4 - Sistema construtivo "steel frame"

Fonte: AL Sistemas Construtivos (2011).
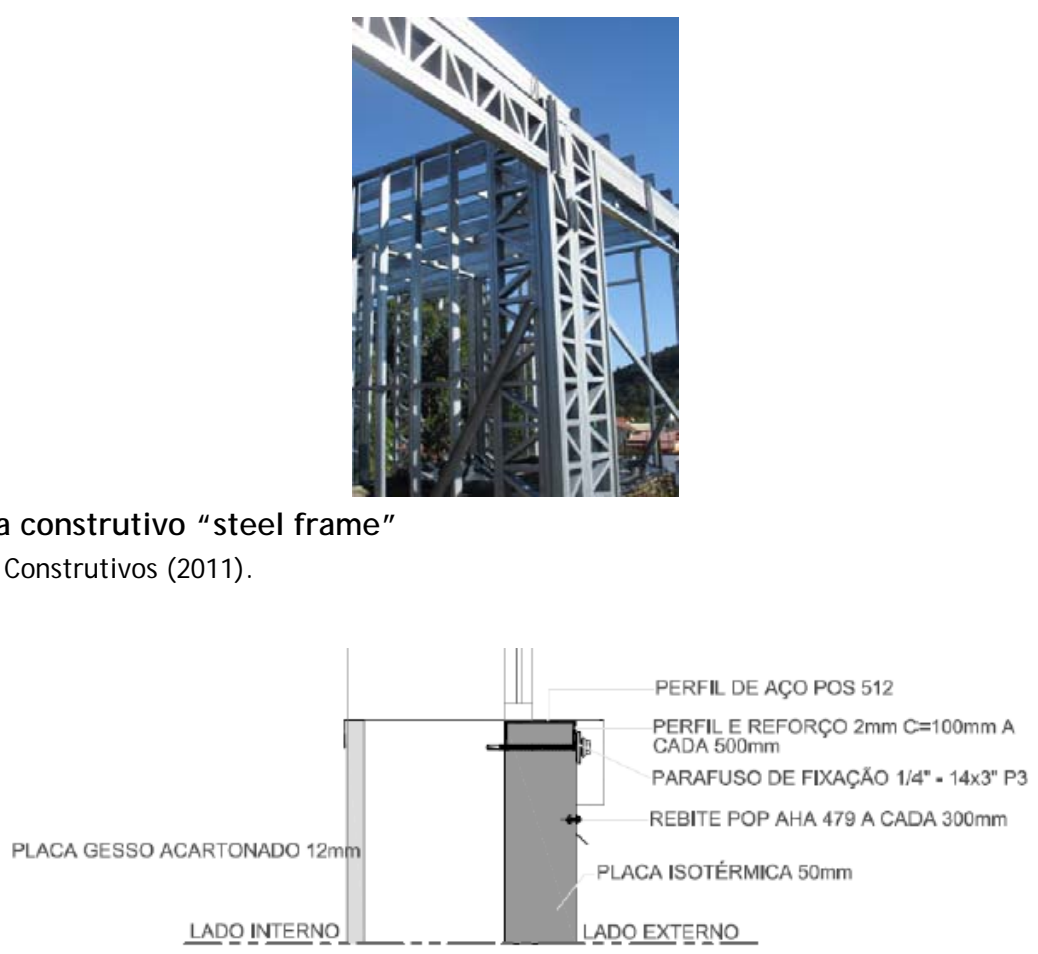

Figura 5 - Detalhe das camadas componentes das paredes externas 


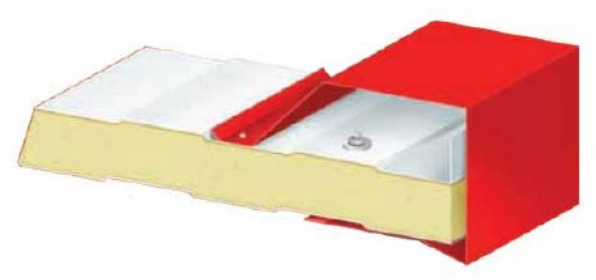

Figura 6 - Telha tipo sanduíche com isolante térmico

Figura 7 - Forro tipo fibra mineral

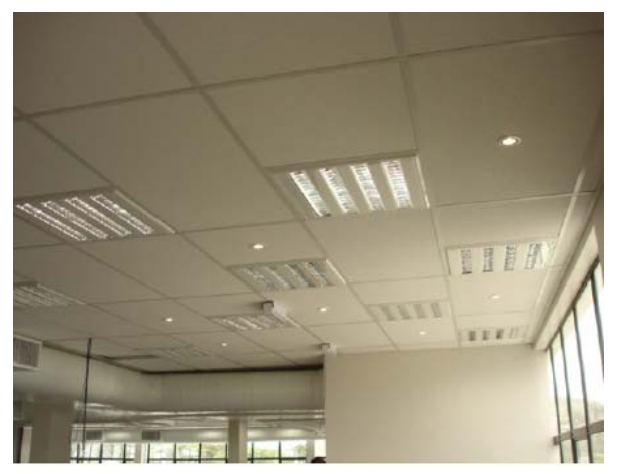

Tabela 9 - Características dos materiais componentes das paredes externas

\begin{tabular}{l|c|c}
\hline \multicolumn{1}{c|}{ Descrição } & e (m) & $\boldsymbol{\lambda}(\mathbf{( W / ( m . K ) )}$ \\
\hline Placa tipo "termowall” de poliuretano 50mm & 0,050 & 0,030 \\
Placa tipo gesso acartonado 12mm & 0,012 & 0,350 \\
\hline
\end{tabular}

Tabela 10 - Características dos materiais componentes da cobertura

\begin{tabular}{l|l|c}
\hline \multicolumn{1}{c|}{ Descrição } & \multicolumn{1}{c|}{$\mathbf{e ~ ( m )}$} & $\boldsymbol{\lambda}(\mathbf{( W / ( m . K ) )}$ \\
\hline Chapa metálica tipo "galvalume" pré-pintada cor branca & 0,00050 & 38,146 \\
Isolante térmico tipo poliuretano (ref. PUR, fab. Dânica), 30 mm & 0,030 & 0,01725 \\
Chapa metálica tipo "galvalume" & 0,00043 & 38,146 \\
Forro mineral (ref. Armstrong, fab. Hunter Douglas) $10 \mathrm{~mm}$ & 0,010 & $.0,0720$ \\
\hline
\end{tabular}

Fonte: Dânica (2012), Knauff (2012), Hunter Douglas (2012), Companhia Siderúrgia Nacional (2012) e ABNT (2005).

A transmitância térmica calculada para as paredes externas do projeto padrão é $U_{\mathrm{par}}=0,490$ $\mathrm{W} /\left(\mathrm{m}^{2} . \mathrm{K}\right)$. Em relação às cores das paredes, externamente a agência possui cores claras, com absortância solar média de $\alpha$ ar $=0,23$, utilizando os dados da Tabela B.2 - absortância $(\alpha)$ para radiação solar (ondas curtas) e emissividade $(\varepsilon)$ para radiações a temperaturas comuns (ondas longas), do Anexo B da NBR 15220 - Parte 2 (ABNT, 2005).

$\mathrm{O}$ valor da transmitância térmica calculado para a cobertura projeto padrão $\mathrm{U}_{\mathrm{cob}}=0,449 \mathrm{~W} /\left(\mathrm{m}^{2} . \mathrm{K}\right)$. Em relação às cores da cobertura, a telha sanduíche possui na face externa uma chapa metálica tipo "galvalume" pré-pintada na cor branca. De acordo com a Tabela B.2 do Anexo B da NBR 15220 - Parte 2 (ABNT, 2005), tem-se o tipo de superfície descrita como "chapa de aço galvanizada (nova e brilhante)", sendo adotado o valor de $\alpha_{\text {cob }}=0,25$ para a absortância média da cobertura do projeto padrão.

O RTQ-C estabelece pré-requisitos específicos para a envoltória, de acordo com o nível de eficiência energética pretendido. Os valores calculados de transmitância térmica das paredes externas $\left(U_{\mathrm{par}}\right)$ e da cobertura $\left(\mathrm{U}_{\mathrm{cob}}\right)$, absortância solar das paredes externas $\left(\alpha_{\text {par }}\right)$ e da cobertura $\left(\alpha_{\mathrm{cob}}\right)$ atendem simultaneamente todos os prérequisitos para o nível "A" de eficiência energética da envoltória, para qualquer uma das 8 zonas bioclimáticas brasileiras.

\section{Parâmetros fixos e variáveis}

Para as equações do ICenv, as seguintes variáveis foram consideradas com valores fixos: $\mathrm{FA}=1,00$; $\mathrm{FF}=0,3277 ; \mathrm{PAF}_{\mathrm{T}}=0,098$ (para implantação do 
projeto com a fachada principal orientada para o norte, leste e sul); $\mathrm{PAF}_{\mathrm{T}}=0,289$ (para implantação do projeto com a fachada principal orientada para o oeste). Já as variáveis FS, AVS e AHS foram consideradas passíveis de alteração, visando à otimização do projeto padrão com valores que tornem sua classificação energética mais eficiente.

\section{Teste de valores de AVS, AHS e FS para análise da envoltória}

Nas situações em que a classificação do nível de eficiência energética da envoltória do projeto padrão não atingiu o nível "A" (mais eficiente) pelo Método Prescritivo do RTQ-C, foram avaliadas alterações nas variáveis em alguns parâmetros das equações do ICenv para as diversas zonas bioclimáticas, tais como proteções solares externas (AVS e AHS) e características técnicas dos vidros (FS), visando à melhoria da classificação do nível de eficiência energética. Para a determinação dos valores otimizados, foi utilizada a ferramenta "Atingir Meta" do Microsoft Excel, tendo como valor a ser atingido o ICenv menor que o ICmín limite para a classificação com o nível "A", variando-se apenas um dos três parâmetros e mantendo-se as demais variáveis fixas.

\section{Metodologia de simulação computacional}

A etiquetagem da eficiência energética de edifícios pode ser realizada através dos Métodos Prescritivo ou de Simulação, de acordo com o RTQ-C. Ambos os métodos devem atender aos requisitos relativos ao desempenho da envoltória, a eficiência e potência instalada do sistema de iluminação e a eficiência di sistema de condicionamento de ar. $\mathrm{O}$ Método de Simulação descrito no RTQ-C compara o desempenho do edifício proposto (real) com um edifício similar (de referência), cujas características devem estar de acordo com o nível de eficiência pretendido. Portanto, dois modelos devem ser construídos: o modelo representando o edifício real (de acordo com o projeto proposto) e o modelo de referência (de acordo com o nível de eficiência pretendido).

A metodologia de simulação proposta neste trabalho difere do Método de Simulação definido no RTQ-C, pois o objetivo da simulação computacional neste estudo é estimar o potencial de economia de energia do sistema de climatização em função de alterações propostas para as aberturas envidraçadas de um projeto padronizado. Para a metodologia proposta neste trabalho, a ferramenta utilizada foi o programa EnergyPlus (que também pode ser utilizado para a etiquetagem de edificações através do Método de Simulação do RTQ-C).

O EnergyPlus é um programa de simulação computacional que objetiva auxiliar o estudo e análise de

edifícios do ponto de vista termoenergético. A ferramenta foi concebida pelo Departamento de Energia dos Estados Unidos a partir de programas já existentes, como o Blast e o DOE-2. O programa simula a carga térmica de uma edificação com base nas descrições e parâmetros previamente definidos pelo usuário. Assim, o EnergyPlus calcula a quantidade de energia necessária para que a temperatura do ar ambiente interior se mantenha dentro dos limites aceitáveis. Como dados de entrada, o EnergyPlus utiliza informações como localização geográfica, geometria e materiais constituintes do edifício, zonas térmicas, arquivos climáticos, equipamentos, iluminação, pessoas e padrões de uso. Como resultados, o programa fornece dados de saída relativos a temperatura exterior, temperatura interior em cada zona térmica, necessidades de energia para aquecimento e resfriamento e trocas de calor pelos elementos da envoltória.

Neste trabalho foi utilizada a versão 6.0 do EnergyPlus para a análise do potencial da redução do consumo de energia elétrica com o sistema de condicionamento de ar em função das alterações propostas na envoltória do projeto padrão. Inicialmente, foram inseridos os dados de entrada do projeto padrão original e executada a simulação para a verificação do gasto energético anual com o sistema de condicionamento de ar. Para a simulação, o EnergyPlus utiliza arquivos climáticos que fornecem valores horários (mínimo 8.760 horas $=1$ ano de dados) para todos os parâmetros relevantes requeridos pelo programa de simulação, tais como temperatura e umidade, direção e velocidade do vento e radiação solar, cujos formatos (TRY, TMY, SWEC, CTZ2 etc.) estão publicados no site do U.S. Department of Energy - Energy Efficiency \& Renewable Energy (U.S. DEPARTMENT..., 2011) e também no site do LabEEE - Laboratório de Eficiência Energética em Edificações (UNIVERSIDADE..., 2012).

Quanto aos padrões de uso ("schedules"), estes foram definidos por zona térmica e pelas cargas envolvidas (iluminação, equipamentos e pessoas). O horário normal de expediente bancário (atendimento ao público) é somente durante os dias de semana, das $10 \mathrm{~h}$ às $16 \mathrm{~h}$. Aproximadamente duas horas antes e duas horas depois do horário de expediente normal, parte dos empregados permanece na agência realizando trabalhos internos (mantendo-se parcialmente ligadas as 
cargas de iluminação, equipamentos e ar condicionado). Esse é o padrão de uso do salão de atendimento da agência. Alguns ambientes internos da agência possuem equipamentos de informática que funcionam 24 horas por dia. Apesar de não haver empregados trabalhando nesses ambientes permanentemente, o calor dissipado pelos equipamentos obriga a instalação de sistemas de ar condicionado que operam em regime contínuo. É o caso da sala técnica e do corredor de manutenção. $\mathrm{Na}$ parte posterior da agência ficam os ambientes de acesso restrito e instalações sanitárias. Por serem ambientes de permanência não prolongada, não necessitam de sistema de climatização especial e por isso são ambientes não condicionados artificialmente. Já a sala de autoatendimento possui horário diferenciado. Funciona sete dias por semana, das $8 \mathrm{~h}$ às $22 \mathrm{~h}$. No horário das $8 \mathrm{~h}$ às $18 \mathrm{~h}$, o sistema de iluminação funciona parcialmente, já que as luminárias próximas às áreas envidraçadas permanecem desligadas (contribuição de luz natural). Das $18 \mathrm{~h}$ às $22 \mathrm{~h}$, todas as luminárias permanecem ligadas. Além do salão de atendimento, é o único ambiente que foi considerado para o conforto térmico de pessoas e que necessita de sistema de climatização artificial. A Figura 8 mostra o comportamento de carga diário de uma agência bancária típica, localizada na Região Sul do Brasil.
Para o projeto padrão, o piso é de concreto com espessura de $10 \mathrm{~cm}$. Conforme o tutorial do EnergyPlus, recomenda-se que a temperatura do solo seja obtida por meio de programas auxiliares (Slab ou Basement), pois esse parâmetro possui grande influência para aplicações residenciais e para pequenas edificações (como é o caso da agência bancária). Caso esses programas não sejam utilizados, pode ser inserido um valor padrão de $2^{\circ} \mathrm{C}$ abaixo do valor médio da temperatura do espaço interno. Para as simulações, foram lançados os valores das temperaturas médias mensais do interior da edificação descontando-se o valor padrão de $2^{\circ} \mathrm{C}$. Os demais fechamentos das zonas térmicas foram inseridos de maneira simplificada, com os dados de resistência térmica e da absortância solar calculados para o Método Prescritivo e valores de catálogo (para os vidros).

Os ângulos verticais de sombreamento (AVS) são proporcionados por brises horizontais ("overhangs") junto às janelas e pelas marquises ("shading zone detailed") na entrada da agência. Já os ângulos horizontais de sombreamento (AHS) são proporcionados por brises verticais ("fins") e também pela volumetria junto à entrada. Como saída da simulação, são gerados arquivos do tipo dxf (desenho) e planilhas no formato csv. Os arquivos gráficos de saída da simulação do projeto padrão original no EnergyPlus são mostrados na Figura 9.

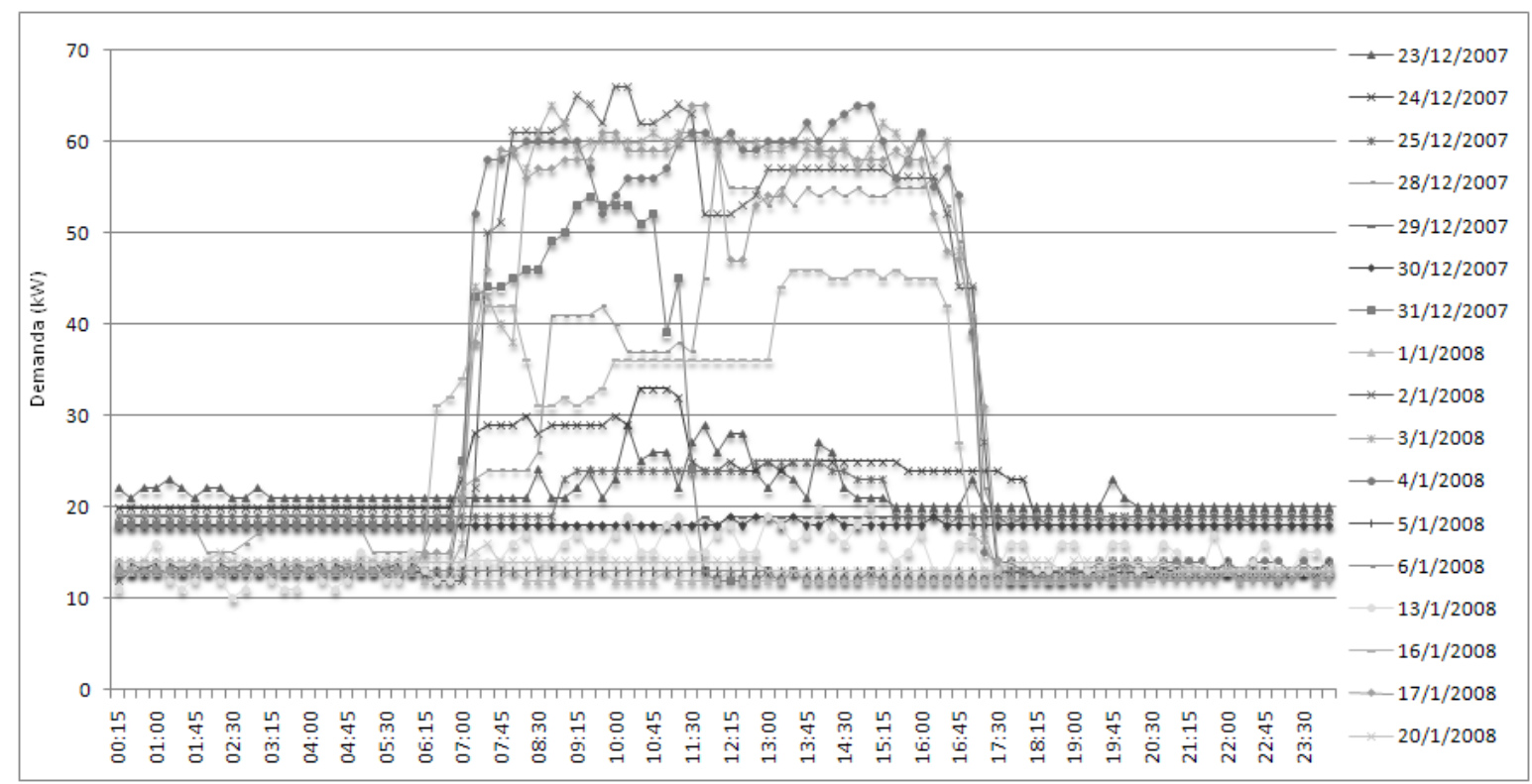

Figura 8 - Comportamento de carga diário de uma agência bancária típica, localizada na Região Sul do Brasil

Fonte: relatório interno da Caixa Econômica Federal (acesso restrito). 


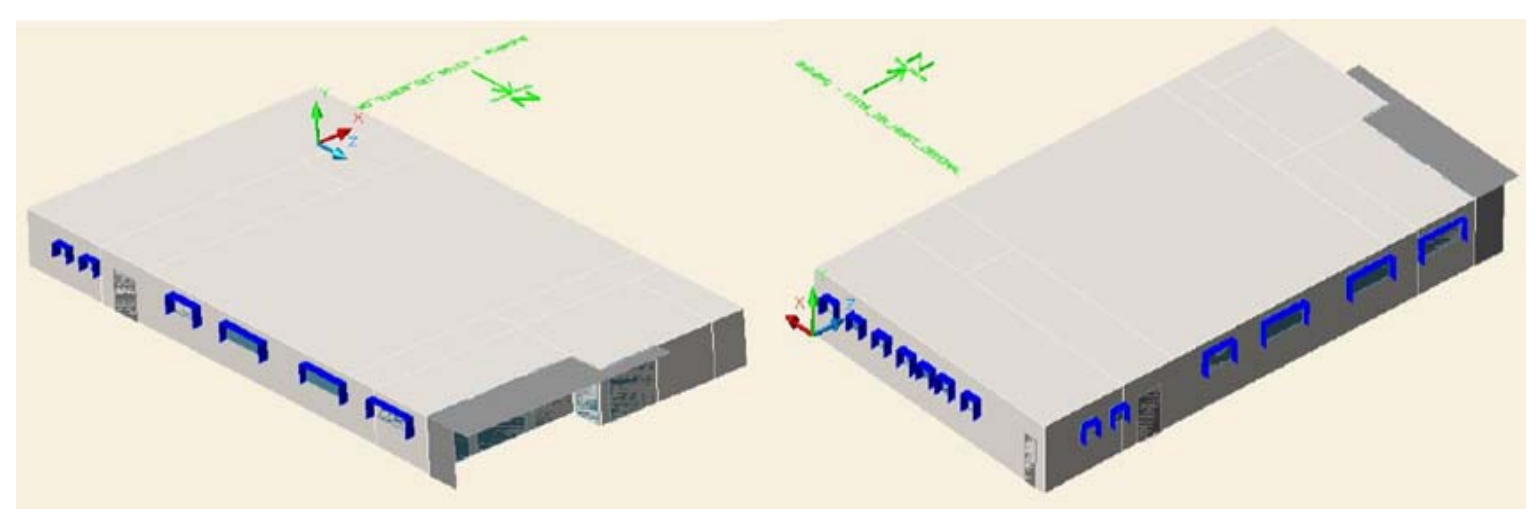

Figura 9 - Vista em 3D do projeto padrão original da agência bancária

Fonte: arquivo gráfico gerado pelo EnergyPlus.

O salão de atendimento foi simulado com a ocupação máxima de 60 pessoas durante o horário normal de atendimento. Já para a sala de autoatendimento, foi previsto que cada uma das seis máquinas estivesse sendo utilizada simultaneamente por um cliente. A taxa metabólica de $117 \mathrm{~W} / \mathrm{m}^{2} /$ pessoa foi baseada em função da atividade predominante no ambiente (digitação). Para as cargas de iluminação, foram inseridos os valores das potências totais para cada uma das cinco zonas internas. A luminária utilizada é do tipo de embutir, com fração radiante de 0,37 e fração visível de 0,18 , de acordo com o tutorial do EnergyPlus. Os equipamentos existentes na agência são basicamente microcomputadores, rack's dos sistemas de cabeamento estruturado e equipamentos de caixas automáticos na sala de autoatendimento.

Por questões de segurança, uma agência bancária possui poucas aberturas com ventilação natural. A taxa de infiltração de ar no salão de atendimento é de aproximadamente $0,005 \mathrm{~m}^{3} / \mathrm{s}$ (taxa de insuflamento de ar prevista no projeto de climatização dos equipamentos centrais, com retornos dutados até a casa de máquinas, onde há a tomada externa para renovação do ar). Os termostatos de cada zona térmica foram ajustados para acionar o sistema de resfriamento quando a temperatura interna for superior a $24^{\circ} \mathrm{C}$ (de acordo com os padrões técnicos da instituição bancária, não é previsto aquecimento para os sistemas de ar condicionado). Os sistemas de ar condicionado ("HVAC") do projeto padrão são do tipo "split unitário". O padrão de uso é em função da utilização por pessoas (salão de atendimento ao público e sala de autoatendimento) ou por equipamentos (sala técnica e corredor de manutenção).

Para o relatório com os dados de saída da simulação, adicionalmente foi montada uma tabela com o uso final de energia elétrica. Como o sistema de iluminação e a carga dos equipamentos de informática são iguais para o projeto padrão independentemente do local de implantação, a ênfase da análise foi em relação ao consumo esperado para o sistema de ar condicionado (ventilação e resfriamento), pois este é influenciado diretamente pelas alterações propostas para a envoltória. A Figura 10 mostra os consumos mensais de energia elétrica por uso final de uma agência bancária típica localizada na Região Sul do Brasil.

Em consulta aos sites do U.S. DOE e LabEEE, os arquivos disponíveis para a simulação computacional são os seguintes: ZB-1 - CuritibaAfonso Pena.838400, ZB-4 - Brasilia.833780 e ZB-7 - Cuiaba-Marechal.Ron.833620 e Petrolina.829840. Para a ZB-5, não foram encontradas localidades com arquivos climáticos para a simulação. Para as simulações deste trabalho, somente foram utilizados os arquivos climáticos dos municípios de Curitiba, Brasília e Cuiabá.

\section{Resultados e discussão \\ Classificação do nível de eficiência energética da envoltória do projeto padrão original por meio do Método Prescritivo do RTQ-C (situação existente)}

Com base nos valores das variáveis arquitetônicas do projeto padrão, foram desenvolvidos os cálculos com a aplicação das equações e tabelas do Método Prescritivo do RTQ-C para as 8 zonas bioclimáticas brasileiras. Considerando-se que em cada zona bioclimática é possível construir a agência em terrenos com quatro diferentes orientações solares da fachada principal, foram analisadas 32 situações possíveis de implantação do projeto padrão, com diferentes resultados para o 
desempenho energético da envoltória. O Quadro 1 mostra a classificação do nível de eficiência energética da envoltória do projeto padrão de acordo com Método Prescritivo do RTQ-C para as 32 situações analisadas.

De acordo com o Quadro 1, verifica-se que em 6 situações não foi atingido o nível "A" para a envoltória do projeto padrão: implantação do projeto com a orientação da fachada principal para o oeste nas zonas ZB-1, ZB-4 e ZB-5, e implantação do projeto com a orientação da fachada principal para norte, leste e sul na zona ZB-7.

\section{Propostas de diretrizes para melhoria do desempenho energético da envoltória do projeto padrão e obtenção da classificação da eficiência energética com o nível "A"}

As diretrizes propostas foram baseadas em algumas estratégicas bioclimáticas em relação às aberturas envidraçadas, como a alteração dos ângulos de sombreamento (AVS e AHS) e características técnicas do vidro (FS), mas sem alteração da área das aberturas $\left(\mathrm{PAF}_{\mathrm{T}}\right)$. Nas equações, as variáveis $\mathrm{FA}$ e $\mathrm{FF}$ foram mantidas fixas, para não alterar a volumetria da edificação.

\section{Alterações de parâmetros do projeto padrão para a Zona Bioclimática ZB-1}

Para a ZB-1, foi proposta a substituição dos vidros laminados da entrada e do salão de atendimento por vidros com FS de 0,79 (resultando no FS médio de 0,80 ). Também foi proposta a retirada todas as proteções solares verticais (AHS médio de $7,70^{\circ}$ ) e a largura da marquise sobre um dos vidros da fachada frontal foi aumentada em 1,65m (AVS médio de $41,38^{\circ}$ ). Com essas alterações, foi obtido o ICenv de 162,20, classificando a eficiência energética da envoltória com o nível " $A$ " para implantação da agência com a fachada principal para o oeste.

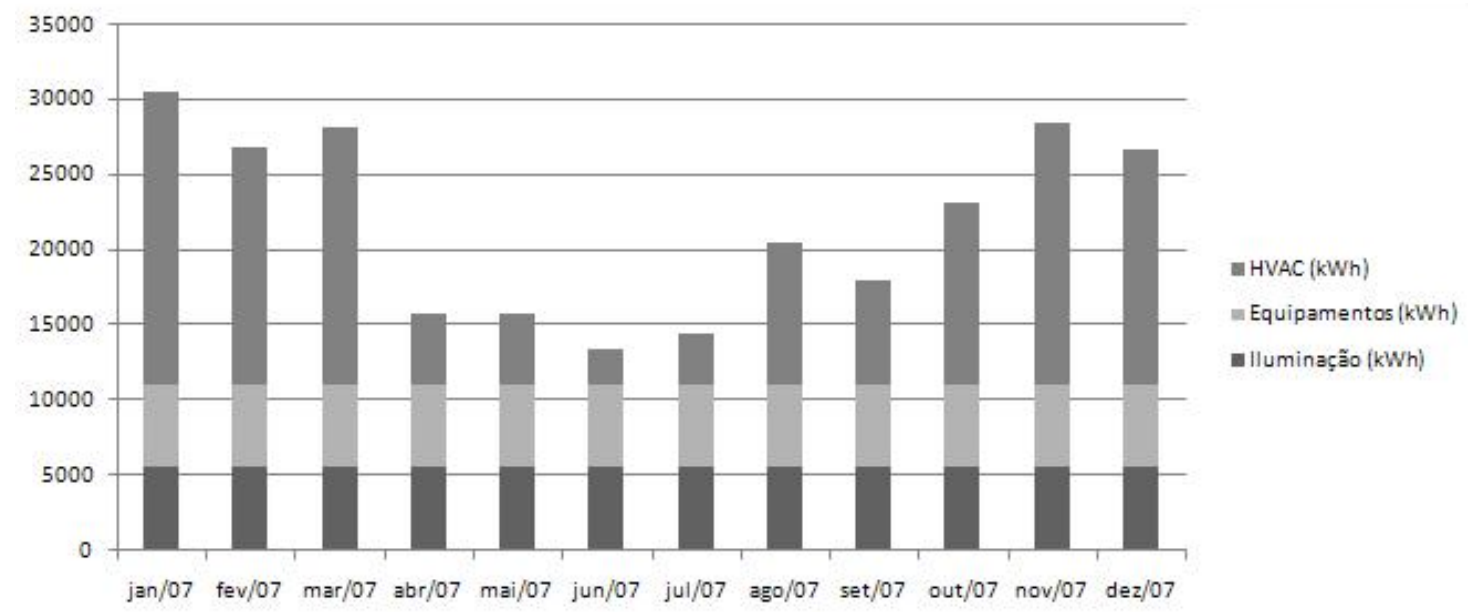

Figura 10 - Consumo de energia elétrica por uso final de uma agência bancária típica, localizada na ZB3, Região Sul do Brasil

Fonte: relatório interno da Caixa Econômica Federal (acesso restrito).

\begin{tabular}{|c|c|c|c|c|}
\hline \multirow{2}{*}{$\begin{array}{c}\text { Zona } \\
\text { Bioclimática }\end{array}$} & \multicolumn{4}{|c|}{ Orientação solar da fachada principal } \\
\cline { 2 - 5 } & Norte & Leste & Sul & Oeste \\
\hline ZB-1 & Nível A & Nível A & Nível A & Nível B \\
\hline ZB-2 & Nível A & Nível A & Nível A & Nível A \\
\hline ZB-3 & Nível A & Nível A & Nível A & Nível A \\
\hline ZB-4 & Nível A & Nível A & Nível A & Nível B \\
\hline ZB-5 & Nível A & Nível A & Nível A & Nível B \\
\hline ZB-6 & Nível A & Nível A & Nível A & Nível A \\
\hline ZB-7 & Nível B & Nível B & Nível B & Nível A \\
\hline ZB-8 & Nível A & Nível A & Nível A & Nível A \\
\hline
\end{tabular}

Quadro 1 - Classificação do nível de eficiência energética da envoltória do projeto padrão original de acordo com Método Prescritivo do RTQ-C 


\section{Alterações de parâmetros do projeto padrão para as Zonas Bioclimáticas ZB-4 e ZB-5}

Para as zonas ZB-4 e ZB-5, foi proposta a utilização vidros laminados de $8 \mathrm{~mm}$ com FS 0,34 para as áreas envidraçadas da entrada da agência e do salão de atendimento, conseguindo-se obter o FS médio de 0,40 . Com essa alteração, foi obtido o ICenv de 468,24, classificando a eficiência energética da envoltória com o nível "A" para implantação da agência com a fachada principal para o oeste.

\section{Alterações de parâmetros do projeto padrão para a Zona Bioclimática ZB-7}

Para otimização da eficiência energética da envoltória para obtenção do nível "A", considerando a implantação da agência com a orientação da fachada principal para o norte, leste e sul, são consideradas três opções distintas.

Como primeira opção, foi proposta a retirada das proteções solares verticais das janelas laterais e dos fundos. Com essa alteração, o AHS médio do projeto passa a ter o valor de $13,10^{\circ}$, resultando no ICenv com o valor de 131,62.

Como segunda opção, foi proposta aumentar a largura da marquise sobre um dos vidros da fachada frontal em 1 metro, resultando no AVS médio de $40,07^{\circ}$. Com isso, o ICenv obtido foi de 133,88. Como terceira opção, foi proposta a substituição do vidro de apenas uma das aberturas (no caso, da janela de $2,00 \mathrm{~m} \times 1,00 \mathrm{~m}$ do salão de atendimento) por um vidro com FS de 0,79, obtendo-se o FS médio de 0,61. Com isso, o ICenv seria 134,09 .

No caso das propostas de melhorias para a Zona Bioclimática ZB-7, a equação do Método Prescritivo mostra que poderia ser executada qualquer uma das propostas anteriores de maneira independente, para obtenção da classificação da envoltória com o nível "A".

\section{Análise das economias de energia por meio de simulação computacional com o programa EnergyPlus}

\section{Zona bioclimática ZB-1 (Curitiba/PR)}

Para o projeto padrão implantado na zona bioclimática ZB-1 com orientação da fachada principal para Oeste, o valor de ICenv para o nível "A" somente é atingido com a retirada de todas as proteções de sombreamento verticais (redução de AHS), aumento do FS médio dos vidros e aumento da largura da marquise sobre a entrada da agência (aumento do AVS). Essa proposta do projeto otimizado foi simulada para o município de Curitiba/PR, apresentando um potencial de economia de energia elétrica de $26,0 \%$ em relação ao projeto original, conforme mostra a Figura 11. Os resultados da simulação validam as alterações propostas para a equação do Método Prescritivo do RTQ-C.

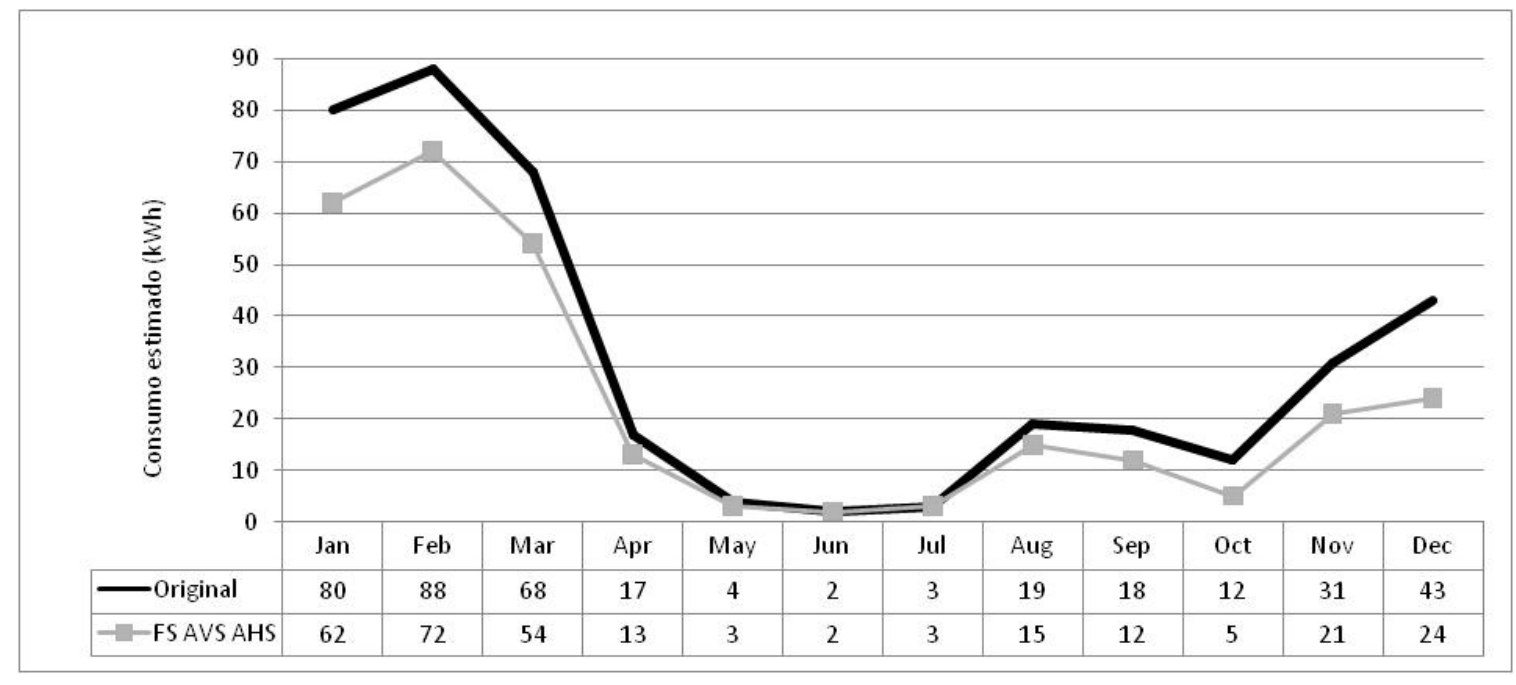

Figura 11 - Potencial de economia de energia elétrica do sistema de ar condicionado, considerando o projeto original e o projeto otimizado, para a implantação do projeto com a fachada principal para 0 oeste na cidade de Curitiba/PR, localizada na ZB-1 - consumo mensal em kWh 


\section{Zona bioclimática ZB-4 (Brasília/DF)}

Para o projeto padrão implantando nas zonas bioclimáticas ZB-4 e ZB-5 com orientação da fachada principal para oeste, a única alternativa viável de acordo com as equações do Método Prescritivo é reduzir o valor do FS médio dos vidros. No caso do município de Brasília/DF (localizado na ZB-4), a simulação mostrou uma economia de até $30,5 \%$ em relação ao projeto original, conforme mostrado na Figura 12. O resultado da simulação valida a equação do ICenv do Método Prescritivo.

\section{Zona bioclimática ZB-7 (Cuiabá/MT)}

Conforme visto, as alterações dos valores na equação do Método Prescritivo para a ZB-7 indicaram três possibilidades para melhoria do projeto original (aumentar o valor médio do FS, aumentar o valor médio do AVS ou reduzir o valor médio do AHS). As simulações computacionais para validação das equações da ZB-7 foram feitas considerando o arquivo climático do município de Cuiabá/MT.

No caso da alteração do FS, a simulação apontou que praticamente não haveria economia em termos de redução de consumo energético em climatização, pois a diferença verificada é insignificante e de apenas $-0,04 \%$ (fachada principal para o norte), $0,04 \%$ (fachada principal para o leste) e $0,5 \%$ (fachada principal para o sul).
Ou seja, a equação do ICenv com a alteração do FS atinge a classificação com o nível " $A$ " de acordo com Método Prescritivo, mas não apresenta relevante potencial de redução do consumo de energia elétrica do sistema de ar condicionado.

Já com a proposta de alteração do projeto com aumento do valor de AVS (aumento da largura da marquise sobre uma das aberturas envidraçadas da fachada principal), as economias verificadas pela simulação foram de 3,9\% para a fachada norte, $2,8 \%$ para a fachada leste e $0,7 \%$ para a fachada sul. Ou seja, a equação do ICenv com o aumento do AVS melhora a classificação da envoltória de acordo com Método Prescritivo e é validada ainda que marginalmente pelos resultados da simulação computacional.

Já a proposta de alteração do projeto padrão com a redução do valor médio de AHS (retirada de proteções solares verticais das janelas) não foi confirmada pela simulação, pois houve indicativo de aumento do consumo de energia elétrica de $1,4 \%$ com a fachada principal para o norte, $1,7 \%$ com a fachada principal para o leste e 3,2\% com a fachada principal para o sul.

As Figuras 13, 14 e 15 mostram a simulação do consumo de energia elétrica do sistema de ar condicionado considerando o projeto original e as alterações propostas para a envoltória, considerando o projeto padrão implantado para as fachadas norte, leste e sul, respectivamente.

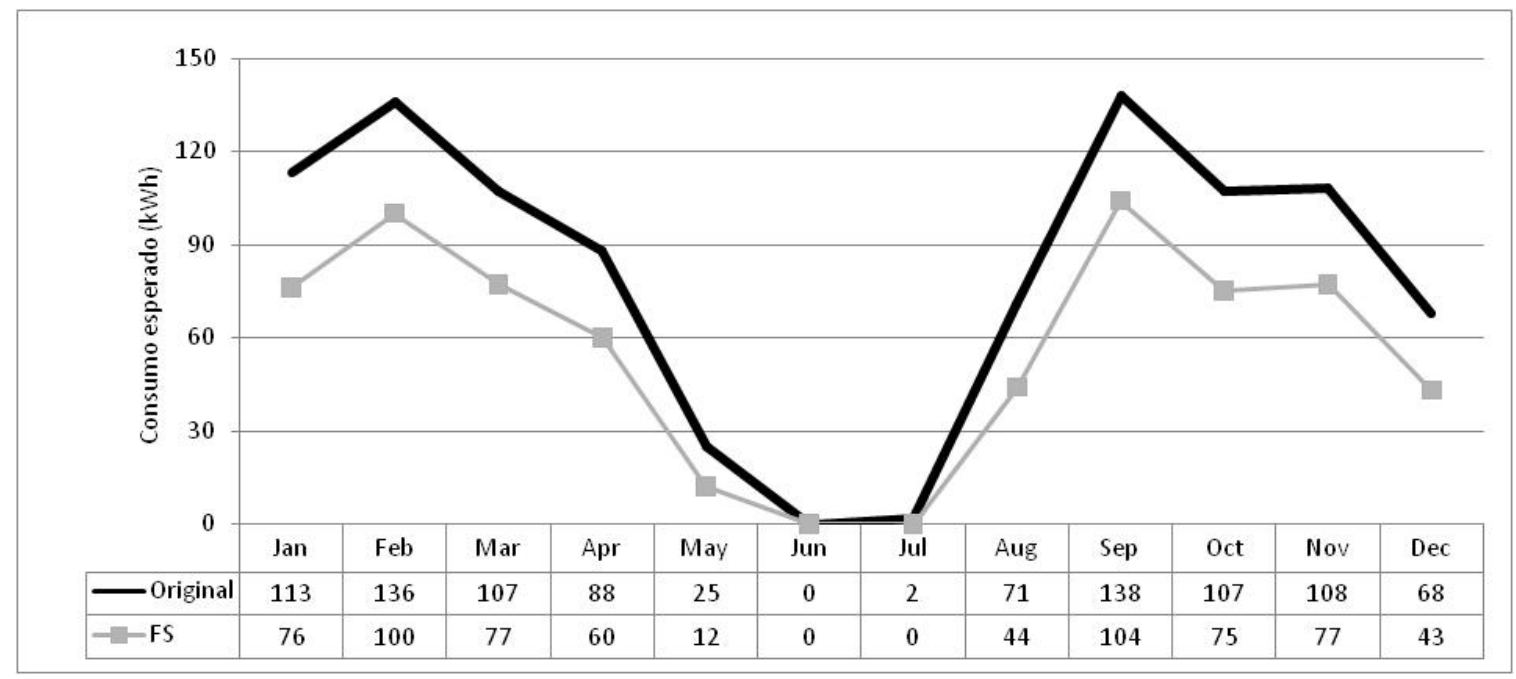

Figura 12 - Potencial de economia de energia elétrica do sistema de ar condicionado, considerando o projeto original e o projeto otimizado, para a implantação do projeto com a fachada principal para 0 oeste na cidade de Brasília/DF, localizada na ZB-4 - consumo mensal em kWh 


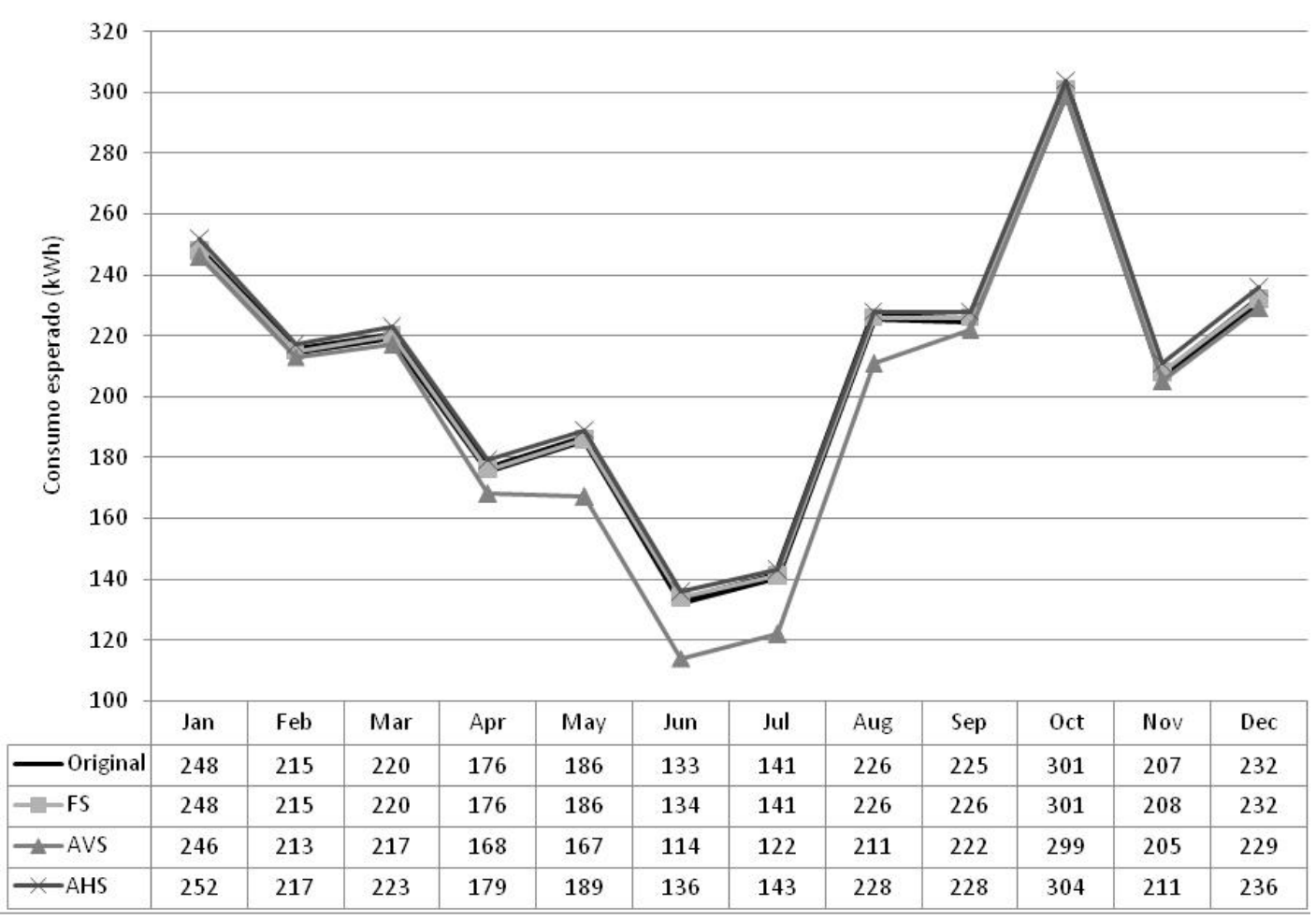

Figura 13 - Potencial de economia de energia elétrica do sistema de ar condicionado, considerando o projeto original e o projeto com as alterações propostas de FS, AVS e AHS, para a implantação da agência com a fachada principal para o norte na cidade de Cuiabá/MT, localizada na ZB-7 - consumo mensal em kWh

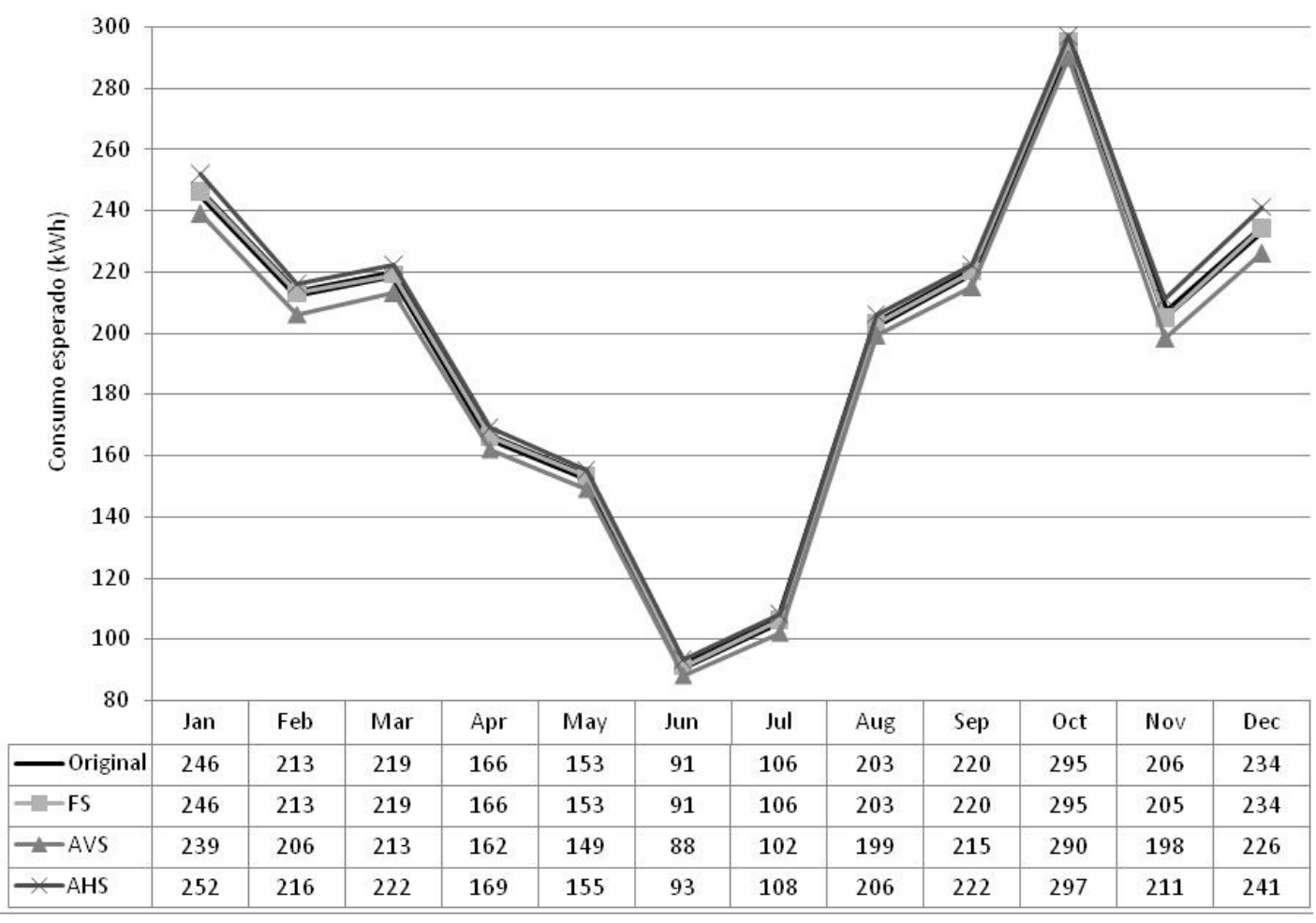

Figura 14 - Potencial de economia de energia elétrica do sistema de ar condicionado, considerando 0 projeto original e o projeto com as alterações propostas de FS, AVS e AHS, para a implantação da agência com a fachada principal para o leste na cidade de Cuiabá/MT, localizada na ZB-7 - consumo mensal em kWh 


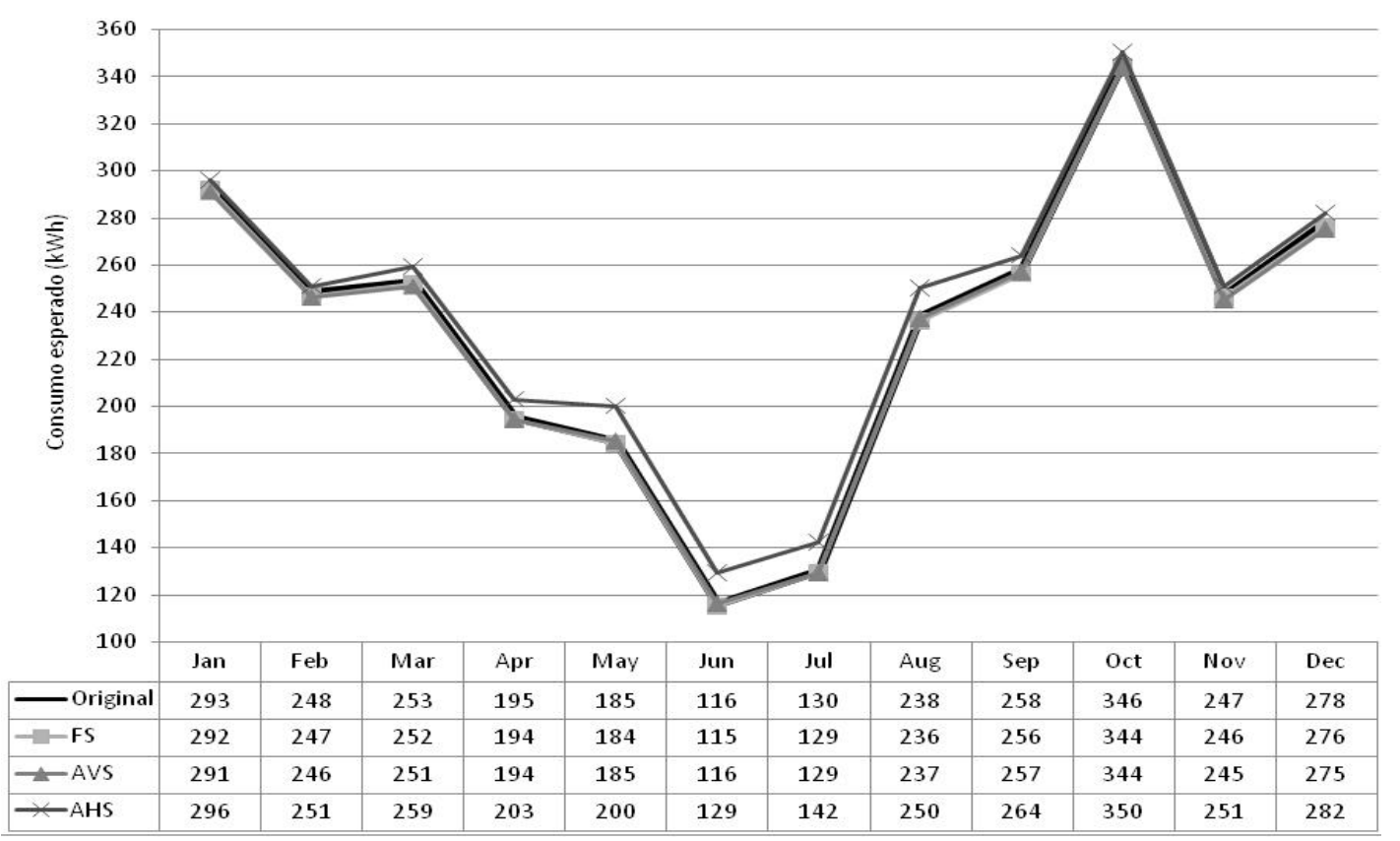

Figura 15 - Potencial de economia de energia elétrica do sistema de ar condicionado, considerando 0 projeto original e o projeto com as alterações propostas de FS, AVS e AHS, para a implantação da agência com a fachada principal para o sul na cidade de Cuiabá/MT, localizada na ZB-7 - consumo mensal em kWh

Tabela 11 - Análise comparativa das alterações propostas para a envoltória e o potencial de redução do consumo de energia elétrica do sistema de ar condicionado

\begin{tabular}{|c|c|c|c|c|c|c|c|c|c|c|c|c|}
\hline \multirow{2}{*}{\multicolumn{2}{|c|}{$\begin{array}{c}\text { Zona } \\
\text { Bioclimática }\end{array}$}} & \multirow{2}{*}{$\begin{array}{l}\text { ZB-1 } \\
\text { Oeste }\end{array}$} & \multirow{2}{*}{$\begin{array}{l}\text { ZB-4 } \\
\text { Oeste }\end{array}$} & \multicolumn{9}{|c|}{ ZB-7 } \\
\hline & & & & \multicolumn{3}{|c|}{ Norte } & \multicolumn{3}{|c|}{ Leste } & \multicolumn{3}{|c|}{ Sul } \\
\hline \multirow{6}{*}{ 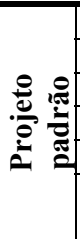 } & FS & 0,60 & 0,60 & \multicolumn{3}{|c|}{0,60} & \multicolumn{3}{|c|}{0,60} & \multicolumn{3}{|c|}{0,60} \\
\hline & AVS & $33,47^{\circ}$ & $33,47^{\circ}$ & \multicolumn{3}{|c|}{$33,47^{\circ}$} & \multicolumn{3}{|c|}{$33,47^{\circ}$} & \multicolumn{3}{|c|}{$33,47^{\circ}$} \\
\hline & AHS & $18,47^{\circ}$ & $18,47^{\circ}$ & \multicolumn{3}{|c|}{$18,47^{\circ}$} & \multicolumn{3}{|c|}{$18,47^{\circ}$} & \multicolumn{3}{|c|}{$18,47^{\circ}$} \\
\hline & ICenv & 164,19 & 493,10 & \multicolumn{3}{|c|}{134,73} & \multicolumn{3}{|c|}{134,73} & \multicolumn{3}{|c|}{134,73} \\
\hline & Classif & B & $\mathrm{B}$ & \multicolumn{3}{|c|}{$\mathrm{B}$} & \multicolumn{3}{|c|}{ B } & \multicolumn{3}{|c|}{ B } \\
\hline & $\begin{array}{c}\text { Consumo } \\
\text { HVAC }\end{array}$ & $\begin{array}{c}385 \\
\mathrm{kWh}\end{array}$ & $\begin{array}{c}963 \\
\mathrm{kWh}\end{array}$ & \multicolumn{3}{|c|}{$2511 \mathrm{kWh}$} & \multicolumn{3}{|c|}{$2353 \mathrm{kWh}$} & \multicolumn{3}{|c|}{$2786 \mathrm{kWh}$} \\
\hline \multirow{6}{*}{ 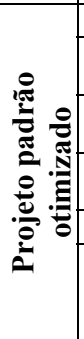 } & FS & $\mathbf{0 , 8 0}$ & $\mathbf{0 , 4 0}$ & 0,60 & 0,60 & 0,61 & 0,60 & 0,60 & 0,61 & 0,60 & 0,60 & 0,61 \\
\hline & AVS & $41,38^{\circ}$ & $33,47^{\circ}$ & $33,47^{\circ}$ & $40,07^{\circ}$ & $33,47^{\circ}$ & $33,47^{\circ}$ & $40,07^{\circ}$ & $33,47^{\circ}$ & $33,47^{\circ}$ & $40,07^{\circ}$ & $\begin{array}{c}33,47 \\
0\end{array}$ \\
\hline & AHS & $7,70^{\circ}$ & $18,47^{\circ}$ & $13,10^{\circ}$ & $18,47^{\circ}$ & $18,47^{\circ}$ & $13,10^{\circ}$ & $18,47^{\circ}$ & $18,47^{\circ}$ & $13,10^{\circ}$ & $18,47^{\circ}$ & $\begin{array}{c}18,47 \\
\text { o }\end{array}$ \\
\hline & ICenv & 162,20 & 468,24 & 131,62 & 133,88 & 134,09 & 131,62 & 133,88 & 134,09 & 131,62 & 133,88 & $\begin{array}{c}134,0 \\
9\end{array}$ \\
\hline & Classif & $\mathbf{A}$ & $\mathbf{A}$ & $\mathrm{A}$ & $\mathbf{A}$ & $\mathrm{A}$ & $\mathrm{A}$ & $\mathbf{A}$ & $\mathrm{A}$ & $\mathrm{A}$ & $\mathbf{A}$ & $\mathrm{A}$ \\
\hline & $\begin{array}{l}\text { Consumo } \\
\text { HVAC } \\
\text { (kWh) } \\
\end{array}$ & $\begin{array}{r}\mathbf{2 8 5} \\
\mathrm{kWh}\end{array}$ & $\begin{array}{r}669 \\
\mathrm{kWh}\end{array}$ & $\begin{array}{l}2547 \\
\mathrm{kWh}\end{array}$ & $\begin{array}{l}\mathbf{2 4 1 3} \\
\mathrm{kWh}\end{array}$ & $\begin{array}{l}2512 \\
\mathrm{kWh}\end{array}$ & $\begin{array}{l}2394 \\
\mathrm{kWh}\end{array}$ & $\begin{array}{l}\mathbf{2 2 8 7} \\
\mathrm{kWh}\end{array}$ & $\begin{array}{l}2352 \\
\mathrm{kWh}\end{array}$ & $\begin{array}{l}2876 \\
\mathrm{kWh}\end{array}$ & $\begin{array}{l}\mathbf{2 7 6 7} \\
\mathrm{kWh}\end{array}$ & $\begin{array}{l}2772 \\
\mathrm{kWh}\end{array}$ \\
\hline \multirow{2}{*}{\multicolumn{2}{|c|}{ Economia }} & $\begin{array}{r}100 \\
\mathrm{kWh}\end{array}$ & $\begin{array}{r}294 \\
\mathrm{kWh}\end{array}$ & $-36 \mathrm{kWh}$ & $98 \mathrm{kWh}$ & $-1 \mathrm{kWh}$ & $-41 \mathrm{kWh}$ & $66 \mathrm{kWh}$ & $1 \mathrm{kWh}$ & $-90 \mathrm{kWh}$ & $19 \mathrm{kWh}$ & $\begin{array}{c}14 \\
\mathrm{kWh}\end{array}$ \\
\hline & & $26,0 \%$ & $30,5 \%$ & $-1,4 \%$ & $3,9 \%$ & $-0,04 \%$ & $-1,7 \%$ & $2,8 \%$ & $0,04 \%$ & $-3,2 \%$ & $0,7 \%$ & $0,5 \%$ \\
\hline
\end{tabular}

\section{Conclusões}

Após o levantamento dos dados do projeto arquitetônico e a aplicação desses valores nas equações do Método Prescritivo do RTQ-C, verificou-se que em apenas seis situações a envoltória não obteve a classificação com o nível "A". Para as zonas bioclimáticas ZB-1, ZB-4 e ZB5, a envoltória foi classificada com o nível "B" para a implantação do projeto com a fachada principal com a orientação solar para o oeste. Para a zona bioclimática ZB-7, a envoltória foi 
classificada com o nível "B" para a implantação do projeto com a fachada principal com a orientação solar para o norte, leste e sul.

A Tabela 11 mostra de forma resumida os dados do projeto padrão original e as alterações propostas, com a nova classificação da eficiência energética da envoltória e os resultados da simulação computacional, com o potencial de redução do consumo de energia elétrica do sistema de ar condicionado.

Desconsiderando-se a alteração do FS para o projeto com orientação solar norte na ZB-7 (cujo valor de $-0,04 \%$ não é relevante), somente não foi verificada a validação da equação do ICenv para a ZB-7 com orientações solares norte, sul e leste, pois a redução do AHS na equação melhora a classificação da envoltória para o nível "A", porém, os resultados da simulação mostraram que essa alteração apresentaria aumento do consumo de energia elétrica com o sistema de ar condicionado.

Para futuras pesquisas, sugere-se o acompanhamento do consumo de energia de uma edificação baseada no projeto padrão já construído, para comparar os resultados previstos em projeto e os valores reais medidos.

Outra sugestão é a formação de banco de dados para futuras comparações realizadas com edifícios de referência (no caso, agências bancárias), que estabelecem qual edificação é mais ou menos eficiente que o de referência. Uma base de dados com diversos edifícios já cadastrados pode gerar benchmarkings, onde se avalia a eficiência de um edifício sendo mais ou menos eficiente em relação a um grupo extenso. Esse grupo pode ser descrito pela atividade institucional ou comercial dos edifícios (que tendem a conter características primárias semelhantes) e podem alcançar abrangência nacional.

\section{Referências}

AGOPYAN, V. et al. Alternativas Para a

Redução do Desperdício de Materiais nos Canteiros de Obras. Relatório final, EPUSP/FINEP/ITQC, 1998. (Coletânea Habitare 2: Inovação, Gestão da Qualidade \& Produtividade e Disseminação do Conhecimento na Construção Habitacional).

AL SISTEMAS CONSTRUTIVOS STEEL FRAME. Catálogo de Produtos. Disponível em: $<$ http://www.alsistemasconstrutivos.com.br/home/i ndex.php>. Acesso em: 12 jun. 2011.
ASSOCIAÇÃO BRASILEIRA DE NORMAS TÉCNICAS. NBR 15220-2: desempenho térmico de edificações: parte 2: métodos de cálculo da transmitância térmica, da capacidade térmica, do atraso térmico e do fator solar de elementos e componentes de edificações. Rio de Janeiro, 2005.

CARLO, J. C. Desenvolvimento de Metodologia de Avaliação da Eficiência Energética do Envoltório de Edificações Não-Residenciais. Florianópolis, 2008. Tese (Doutorado em Engenharia Civil) - Programa de Pós-Graduação em Engenharia Civil, Universidade Federal de Santa Catarina, Florianópolis, 2008.

COMPANHIA SIDERÚRGICA NACIONAL. Catálogo: CSN Galvalume. Acesso em: $<$ http://www.google.com.br/url? sa $=$ t\&rct $=$ j\&q $=\& e$ $\mathrm{src}=\mathrm{s} \&$ source $=$ web $\& \mathrm{~cd}=2 \& \mathrm{cad}=\mathrm{rja} \& \mathrm{ved}=0 \mathrm{CDwQ}$ FjAB\&url=http $\% 3 \mathrm{~A} \% 2 \mathrm{~F} \% 2 \mathrm{Fwww}$.texasfer.com.b r\%2Findex.php\%3Foption\%3Dcom_docman $\% 26 \mathrm{t}$ ask\%3Ddoc_download\%26gid\%3D-11\%26Itemid \%3D2\&ei=-NRFIUPztDI_a8wS96YFY\&usg=AFQ jCNHKe1j10JazCX8hmavyqnnQePo6-A>. Acesso em: 23 set. 2012.

DÂNICA. Catálogo: construção civil, cobertura e fechamento - PUR/PIR EPS. Disponível em: $<$ http://www.danicacorporation.com/sfDanica2/we b/uploads/catalogo/0f267a7a5d6f741701d6e0b42b daa490.pdf>. Acesso em: 23 set. 2012.

EMPRESA DE PESQUISA ENERGÉTICA.

Balanço Energético Nacional 2011. 2011.

Disponível em:

$<$ https://ben.epe.gov.br/BENRelatorioFinal2010.as px>. Acesso em: 11 jan. 2012.

HUNTER DOUGLAS. Forros Minerais.

Disponível em:

$<$ http://www2.hunterdouglas.com.br/html_sp/prod arq_forros_minerais.htm>. Acesso em: $2 \overline{3}$ set. $\overline{2} 012$.

INSTITUTO NACIONAL DE METROLOGIA, NORMALIZAÇÃO E QUALIDADE INDUSTRIAL. Portaria no 372, de 10 de setembro de 2010, aprova a revisão do Regulamento Técnico da Qualidade do Nível de Eficiência Energética de Edifícios Comerciais, de Serviços e Públicos. Disponível em: $<$ http://www.inmetro.gov.br/legislacao/rtac/pdf/RT AC001599.pdf>. Acesso em: 10 dez. 2011.

KNAUFF. [Catálogos da Knauff Drywall]. Disponível em: $<$ http://knauf.com.br/?id=249>. Acesso em: 23 set. 2012. 
KRONKA, R. Impacto e Consumo Energético Embutido em Materiais de Construção: técnicas construtivas. Dissertação (Mestrado em Energia) Instituto de Eletrotécnica e Energia, Universidade de São Paulo, 1998.

LAMBERTS, R.; DUTRA, L.; PEREIRA, F. Eficiência Energética na Arquitetura. São Paulo: PW, 1997. 188 p.

MINISTÉRIO DE MINAS E ENERGIA; EMPRESA DE PESQUISA ENERGÉTICA. Plano Nacional de Energia 2030. Brasília: MME; EPE, 2007.

OLIVEIRA, B. F. et al. Um Modelo de Avaliação do Grau de Aplicação de Ferramentas Lean em Empresas Construtoras: o Rapid Lean Construction-Quality Rating Model (LCR).

Revista Iberobrasileira de Engenharia Industrial, v. 2, n. 2, p. 156-174, 2010.
OLOFSSON, T.; MEIER, A.; LAMBERTS, R. Rating the Energy Performance of Buildings. International Journal of Low Energy and Sustainable Buildings, v. 3, p. 1-18, 2004.

SILVA, V. G. Avaliação da Sustentabilidade de Edifícios de Escritórios Brasileiros: diretrizes e base metodológica. Tese (Doutorado em Engenharia Civil) - Escola Politécnica, Universidade de São Paulo, São Paulo, 2003.

\section{U.S. DEPARTMENT OF ENERGY.}

ENERGYPLUS, versão 6.0. U.S. Department of Energy, Energy Efficiency and Renewable Energy, 2011. Disponpivel em: $<$ http://www.eere.energy.gov $>$. Acesso em: 23 set. 2012.

Revista Ambiente Construído

Associação Nacional de Tecnologia do Ambiente Construído

Av. Osvaldo Aranha, 99 - 3o andar, Centro

Porto Alegre - RS - Brasil

CEP 90035-190

Telefone: +55 (51) 3308-4084

Fax: +55 (51) 3308-4054

www. seer. ufrgs. br/ ambienteconstruido

E-mail: ambienteconstruido@ufrgs.br 